\title{
A STUDY ON THE CHARACTERIZATION OF RED MUD
}

\author{
Harjeet Nath ${ }^{1}$, Abanti Sahoo². \\ 1,2Department of Chemical Engineering, \\ National Institute of Technology, Rourkela, India \\ Email: 1harjeetnath@gmail.com
}

\begin{abstract}
Red Mud (RM) is a solid waste product obtained from aluminum industries via Bayer's process. India is one of the largest producers of RM producing around 4 million tons annually. Its disposal is one of the major concerns as it is highly alkaline in nature and is a potential threat to air, water and land. Currently RM is being dumped on land or in RM ponds near the alumina refineries and with the cost of the land going high it is becoming a big problem for the industries. Due to the differences in the ore type in its production process, there is a variation in the mineralogical composition between the residues from India and other countries. Its properties such as iron content in the form of ferric oxide $\left(\mathrm{Fe}_{2} \mathrm{O}_{3}\right)$, high surface area etc. makes it attractive potential reactants for many reactions. In this paper the structural and phase compositions of RM is being studied with the help of PSA, XRD, FESEM, EDX, BET and FT-IR techniques.
\end{abstract}

Key words: Red Mud, PSA, XRD, FESEM, EDX, FT-IR

\section{INTRODUCTION}

Red Mud (RM) is a solid waste product obtained from aluminum industries which is reddish brown in color. RM is mainly made up of oxides of iron, aluminum, silicon and titanium. The primary composition of red mud is $\mathrm{Al}_{2} \mathrm{O}_{3}(17-20 \%), \mathrm{Fe}_{2} \mathrm{O}_{3}$ (48$54 \%$ ), $\mathrm{SiO}_{2}(4-6 \%), \mathrm{TiO}_{2}(3-4 \%), \mathrm{Na}_{2} \mathrm{O}(3-5 \%), \mathrm{CaO}$ (1$2 \%)$ [1]. RM is usually considered as an inert solid waste but it is strongly alkaline and highly corrosive in nature [2]. It is usually discharged as highly alkaline slurry $(\mathrm{pH} \mathrm{10-13.5)}$ with $15-40 \%$ solids from the industries and because of this highly alkaline character, its disposal is a big problem for the industries as it may lead to soil, water and air pollution. The chemical and mineralogical composition of RM may however slightly change, depending on the source of bauxite and on the technological processing conditions. It is reported that $0.8-1.5$ tons of red mud is generated per ton of alumina produced [3]. Globally $60-120$ million tons of RM is produced annually and about 2 million tons of RM is produced in India [4].

RM can be utilized in various ways like recovery of $\mathrm{Fe}, \mathrm{Al}, \mathrm{Na}$ [5], use in cement production [6], brick production [7], glass production [8], aerated concrete blocks [9], absorb heavy metallic ions like $\mathrm{Cu}^{2+}, \mathrm{Zn}^{2+}$, $\mathrm{Ni}^{2+}, \mathrm{Cd}^{2+}[10]$ and also for the removal of $\mathrm{H}_{2} \mathrm{~S}$ [11] and
Fluoride [12]. During recent years various studies have been carried out on the physical and chemical properties but the characterization results obtained in each case varies from place to place. In the present paper RM sample is analyzed by PSA, XRD, FESEM, EDX and FT-IR and BET techniques. This research gives emphasize on the comprehensive utilization of RM and provides an important base for further studies of it.

\section{MATERIAL AND EXPERIMENTAL METHODS}

\section{A. Materials}

The Red Mud used in this study is collected from NALCO, Damanjodi, Odisha, India. The samples are obtained in slurry form. On drying this slurry, RM lumps are produced. The collected RM lumps are sieved after ball milling it for 45 minutes. The average particle size of RM is found to be 63 microns by sieve analysis. The samples are then stored in plastic sealed packets for further analysis.

\section{B. Experimental Methods}

The particle size of the RM samples is measured using Malvern Mastersizer (Range: $0.02 \mu$ to $2000 \mu$ ). The XRD patterns are analyzed using Philips X'Pert XRay diffractometer with a $\mathrm{Cu}$ Ka radiation source in a 
$2 \theta$ range of $10^{\circ}$ to $70^{\circ}$ at spanning range of $3^{\circ} \mathrm{min}^{-1}$. FESEM and Energy Dispersive X-Ray (EDX) are used to study the surface morphology and elemental composition of the samples respectively using Nova Nano SEM 450. The FR-IR spectra of the samples are obtained by using Perkin Elmer FT-IR Spectrometer (Spectrum RX-I). The range is taken between $4000-400$ $\mathrm{cm}^{-1}$. The BET surface area of the samples is also measured by Quantachrome Autosorb-1 using liquid $\mathrm{N}_{2}$.

\section{RESULTS AND DISCUSSIONS}

\section{A. PSA Analysis:}

The particle size distribution graph of the RM particle is shown in Fig.1. It can be observed that the particle size of the sieved RM particle varies from $0.0136 \mu$ to $990.5362 \mu$ with an average particle size of $12.106 \mu$.Such wide range of particle size is observed because simple sieving using a sieve shaker is just a raw method to obtain a specific particle size

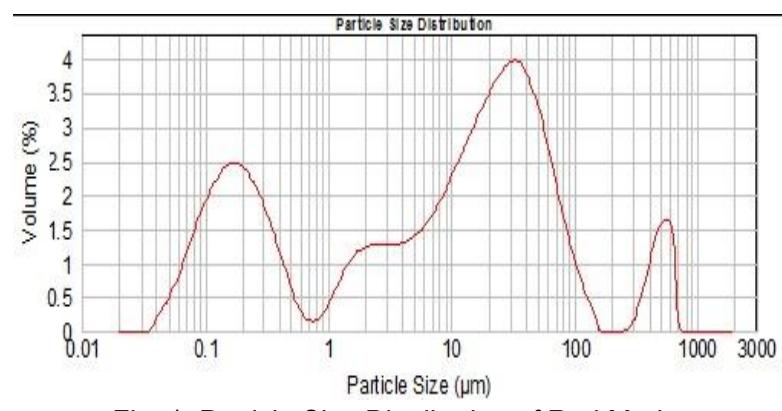

Fig. 1. Particle Size Distribution of Red Mud

\section{B. XRD Analysis:}

The elemental analysis and phase characterization of RM have been reported many times before but the analysis data of the composition of RM is not uniform. From Fig. 2 it can be seen that the main components are Hematite $\left(\mathrm{Fe}_{2} \mathrm{O}_{3}\right)$, Gibbsite $\left(\mathrm{Al}(\mathrm{OH})_{3}\right)$, Rulite $\left(\mathrm{TiO}_{2}\right)$, Calcite $\left(\mathrm{CaCO}_{3}\right)$, Sodium aluminum silicate $\left(\mathrm{Na}\left(\mathrm{AlSiO}_{4}\right)\right)$, Dicalcium silicate $\left(\mathrm{Ca}_{2} \mathrm{SiO}_{4}\right)$, and Quartz $\left(\mathrm{SiO}_{2}\right)$. The XRD pattern of the elements are referred form JCPDS file of X'Pert HighScore software. Using peak broadening technique of X'Pert HighScore software for XRD analysis, one can clearly differentiate the peaks.

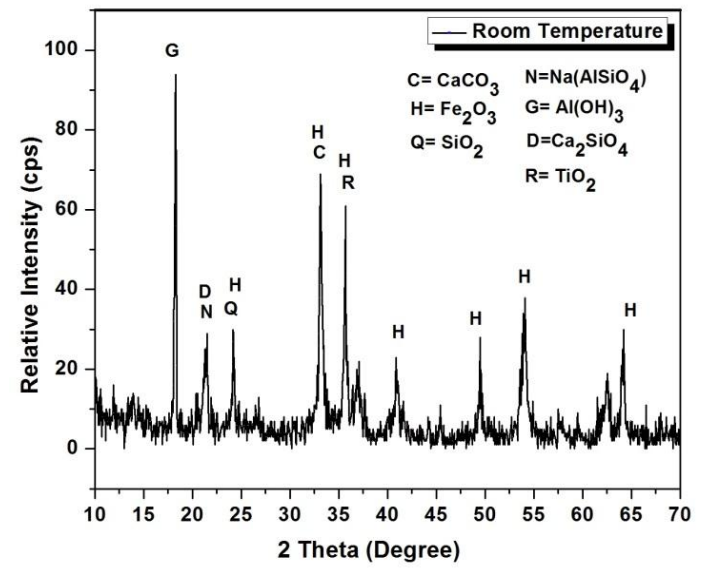

Fig. 2. XRD pattern of Red Mud

\section{FE-SEM and EDX Analysis:}

To analyze the morphological structure of the RM sample, the sample is dispersed in methanol and ultrasonicated for 45 minutes. Then the samples are observed under Field Emission Scanning Electron Microscopy. The FESEM images of RM sample is shown in Fig. 3. It is observed that the arrangement of the particles is relatively loose with high porosity and small particle size.

The EDX analysis of the RM sample ensures the presence of particular elements in it and is shown in Fig. 6. The main elements observed are $\mathrm{Fe}, \mathrm{O}, \mathrm{Ti}, \mathrm{Al}$ and $\mathrm{Si}$.

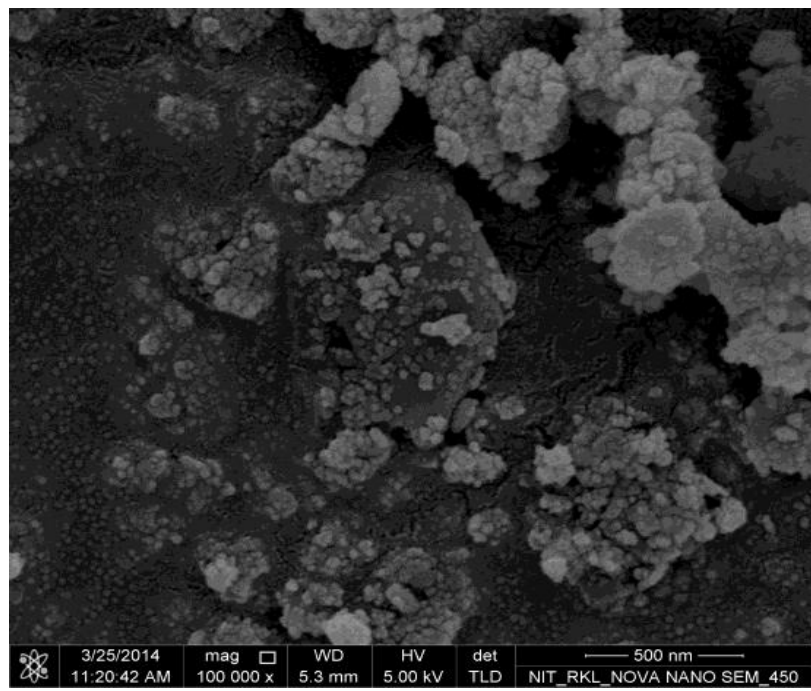




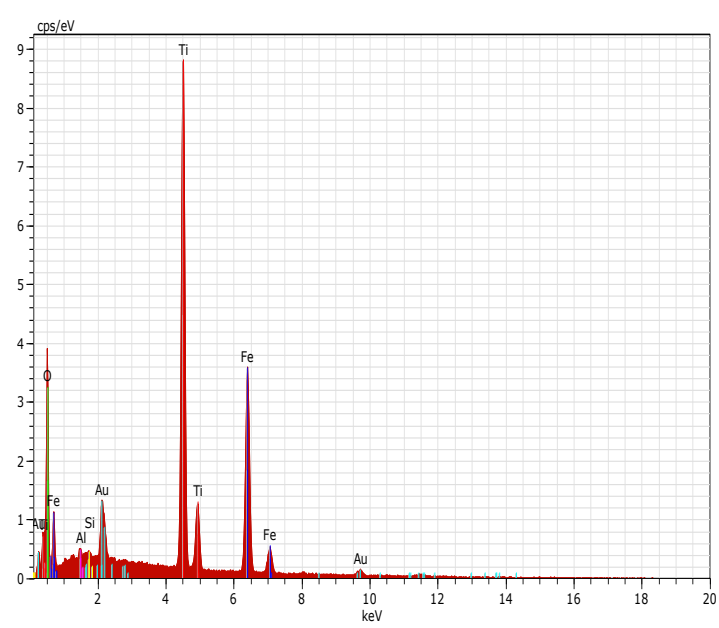

Fig. 4.EDX analysis of Red Mud

\section{FT-IR Analysis:}

The relative FT-IR spectrum of RM is shown in Fig. 7. It is observed from the figure that broad bands occurred around $2919.50 \mathrm{~cm}^{-1}$. This may be due to the stretching vibrations of $\mathrm{O}-\mathrm{H}$ bonds and $\mathrm{H}-\mathrm{O}-\mathrm{H}$ bending vibrations of interlayer adsorbed $\mathrm{H}_{2} \mathrm{O}$ molecule [13]. Here the change in the dipole moment of the water hydroxyl-stretching plays an important role and so the intensity of the infrared spectrum is more. Stretching vibrations of $\mathrm{C}=0$ is found at $1449.40 \mathrm{~cm}^{-1}$ confirms the presence of carbonate groups [14]. The main reason being the presence of chemisorbed $\mathrm{CO}_{2}$ in $\mathrm{RM}$. Characteristic bands of Si-O and O-Si-O group are also observed at $989.30 \mathrm{~cm}^{-1}$ and $534.50 \mathrm{~cm}^{-1}$ confirms the presence of silicate groups. Presence of $\mathrm{Al}^{3+}-\mathrm{O}^{2-}$ bonds are also observed near $805.5 \mathrm{~cm}^{-1}$. Minor stretching vibrations of $\mathrm{Fe}-\mathrm{O}$ is also observed in the region around $440 \mathrm{~cm}^{-1}$.

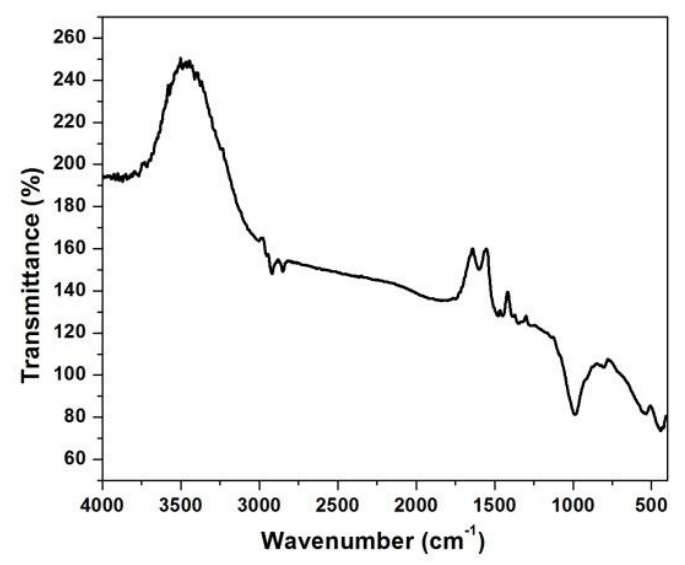

Fig. 5.FT-IR analysis of Red Mud

\section{E. BET Analysis:}

The sample is outgassed at a temperature of $150^{\circ} \mathrm{C}$ for about 1.5 hours. The surface area observed is $32.20 \mathrm{~m}^{2} / \mathrm{g}$ and the pore volume being $0.175 \mathrm{~cm}^{3} / \mathrm{g}$. Thus the analysis suggests that the surface area of the RM sample is quite descent to make it use as a reactant or a catalyst till some extent.

\section{CONCLUSIONS}

In this paper using the PSA analysis, the average particle of the RM sample is found to be $12.106 \mu$. The XRD results shows the presence of certain compounds which are again confirmed by the EDX and FT-IR analysis. The FESEM image shows the morphological structure of RM where the particles are relatively loose or particles are poorly crystallized and with high porosity. The BET analysis shows that the RM sample has a descent surface area. All the obtained results will provide an important base for the further studies of comprehensive utilization of RM.

\section{REFERENCES}

[1] Fois, A. Lallai, G. Mura, Sulfur dioxide absorption in a bubbling reactor with suspensions of Bayer red mud, Ind. Eng. Chem. Res. 46 (2007) 6770-6776.

[2] Chaddha MJ, Rai SB, Goyal RN. (2007). ENVICON 2007, National seminar on environmental concern and remedies in Alumina Industry at NALCO, Damanjodi, India. Characteristics of red mud of Indian Alumina Plants and their possible utilization. 2007, 41-44.

[3] Liu X, Zhang N. Waste Management \& Research. 2011; (29):1053-1063.

[4] Agrawal A, Sahu KK, Pandy BD. Solid waste management in non-ferrous industries in India. Resources, Conservation and Recycling. 2004;(42):99 120.

[5] Y. F. Sun, F.Z. Dong, and J.T. Liu, Technology for recovering iron from red mud by Bayer process, Metal Mine, vol. 9, pp. 176-178, 2009 (Chinese).

[6] X. R. Qiu and Y. Y. Qi, The reasonable utilization of red mud in cement production, Cement Technology, vol. 6 , pp. 103- 105, 2011.

[7] P. Yang, The development of brick made of red mud and fly ash, Light Metals, vol. 12, pp. 17-18, 1996.

[8] J. K. Yang, D. D. Zhang, and B. Xiao, Study on glassceramics mostly made from red mud and fly ash, Glass \& Enamel, vol. 32, pp. 9-11, 2004 (Chinese). 
[9] B. Wu, D. C. Zhang, and Z. Z. Zhang, The study of producing aerated-concrete blocks from red-mud, China Resources Comprehensive Utilization, vol. 6, pp. 29-31, 2005

[10] M. Vaclavikova, P. Misaelides, G. Gallios, S. Jakabsky, and S. Hredzak, Removal of cadmium, zinc, copper and lead by redmud, an iron oxides containing hydrometallurgical waste, Studies in Surface Science and Catalysis, vol. 155, pp. 517-525, 2005

[11] R.C.Sahu, R.K. Patel, B.C.Ray, Removal of hydrogen sulfide using red mud at ambient conditions, Fuel Processing Technology 92 (2011) 1587-1592.

[12] Y.Cengeloglu, E.Kır, M.Ersoz., Removal of fluoride from aqueous solution by using red Mud, Separation and Purification Technology 28 (2002) 81-86.

[13] R.C.Sahu, R.K.Patel, B.C.Ray, Neutralization of red mud using $\mathrm{CO} 2$ sequestration cycle, Journal of Hazardous Materials 179 (2010) 28-34.
[14] C. Cardell, I. Guerra, J. Romero-Pastor, G. Cultrone, A. Rodriguez-Navarro, Innovative analytical methodology combining micro-X-ray diffraction, scanning electron microscopy-based mineral maps, and diffuse reflectance infrared Fourier transform spectroscopy to characterize archeological artifacts, Anal. Chem. 81 (2) (2009) 604611

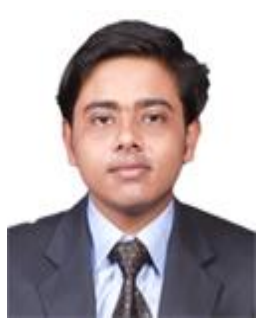

Mr. Harjeet Nath is currently pursuing M.Tech (Research) at National Institute of Technology, Rourkela, Odisha, India. His areas of interest include "Fluidized Bed Reactor", "Modeling and Simulation", "Reaction Kinetics" and "Industrial Effluent Control and Treatment ". 